\title{
Impact of concomitant injuries on outcomes after traumatic brain injury
}

\author{
Johannes Leitgeb • Walter Mauritz • \\ Alexandra Brazinova $\cdot$ Marek Majdan • \\ Ingrid Wilbacher
}

Received: 22 October 2012/Published online: 5 March 2013

(C) The Author(s) 2013. This article is published with open access at Springerlink.com

\begin{abstract}
Background Patients with traumatic brain injury (TBI) frequently have concomitant injuries; we aimed to investigate their impact on outcomes.

Methods Between February 2002 and April 2010, 17 Austrian centers prospectively enrolled 863 patients with moderate and severe TBI into observational studies. Data on accident, treatment, and outcomes were collected. Patients who survived until intensive care unit (ICU) admission and had survivable TBI were selected, and were assigned to "isolated TBI" or "TBI + injury" groups. Sixmonth outcomes were classified as "favorable" if Glasgow Outcome Scale (GOS) scores were five or four, and were
\end{abstract}

The Austrian Severe TBI Study Group membrs are listed in the "Appendix".

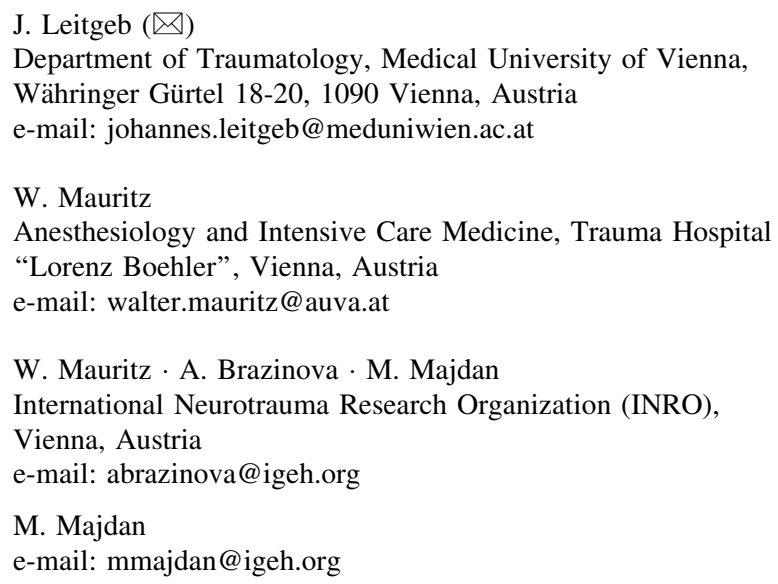

classified as "unfavorable" if GOS scores were three or less. Univariate statistics (Fisher's exact test, $t$ test, $\chi^{2}$-test) and logistic regression were used to identify factors associated with hospital mortality and unfavorable outcome. Results Of the 767 patients, $403(52.5 \%)$ had isolated TBI, $364(47.5 \%)$ had concomitant injuries. Patients with isolated TBI had higher mean age (53 vs. 44 years, $P=0.001$ ); hospital mortality (30.0 vs. $27.2 \%, P=0.42$ ) and rate of unfavorable outcome (50.4 vs. $41.8 \%$, $P=0.02)$ were higher, too. There were no significant mortality differences for factors like age groups, trauma mechanisms, neurologic status, CT findings, or treatment factors. Concomitant injuries were associated with higher mortality (33.3 vs. $12.5 \%, P=0.05)$ in patients with moderate TBI, and were significantly associated with more ventilation, ICU, and hospitals days. Logistic regression revealed that age, Glasgow Coma Scale score, pupillary reactivity, severity of TBI and CT score were the main factors that influenced outcomes.

Conclusions Concomitant injuries have a significant effect upon the mortality of patients with moderate TBI. They do not affect the mortality in patients with severe TBI. Level of evidence and study type Evidence level 2; prospective, observational prognostic study.

Keywords Traumatic brain injury - Outcome . Concomitant injuries

\section{Introduction}

A significant number of patients with traumatic brain injury (TBI) have concomitant injuries. These injuries may vary in severity, and their impact may vary accordingly. It has been reported that $40 \%$ of the patients with severe TBI die from 
non-neurological causes, with higher incidence in patients with multiple injuries [1]. A German analysis found that mortality after head injury was $5 \%$ higher in patients with severe concomitant injuries [2]. Another study reported that in patients with epidural hematoma $(\mathrm{EDH})$ outcomes were not worsened by the presence extracranial injuries [3]. The goal of this study was to investigate the influence of concomitant injuries upon the outcomes of patients with moderate to severe TBI. Our hypothesis was that concomitant injuries would increase mortality after TBI.

\section{Patients and methods}

Between 2001 and 2010, the International Neurotrauma Research Organization (INRO, founded 1999; based in Vienna, Austria) coordinated two projects that focused on Austrian patients with TBI. Databases developed by INRO were used to collect data for both projects. In the first project epidemiology and hospital treatment of patients with severe TBI as well as the effects of guideline-based treatment were analyzed [4]. This project started in March 2002; five centers enrolled 415 patients until June 2005. The second project focused on prehospital and early hospital management of patients with moderate and severe TBI. It started in March 2009; 16 centers enrolled 448 patients until April 2010. Both projects were done with approval of the local Ethical Committees.

\section{Centers}

Seventeen Austrian centers participated in these projects, all were of tertiary care level and were able to provide guidelinebased [5] patient management. The changes made during the revisions of these guidelines in 2000 and 2007, respectively, were taken into account. The number of patients enrolled by these centers (median: 28, IQR 21-65, range 3-150) varied considerably, as four centers participated in both projects, and some centers joined the second project with just few weeks remaining for patient inclusion. Hospital mortality for patients with severe TBI was significantly lower during the 2009-2010 projects (28 vs. $37 \%$; $P=0.005$ ). However, Glasgow Coma Scale (GCS) score was significantly lower (5.4 vs. $5.9 ; P=0.022$ ) and Abbreviated Injury Score (AIS) for the region "head" was significantly higher (4.2 vs. 3.9; $P<0.001$ ) in the patients from the 2002-2005 projects; thus, "period of enrollment" was not significantly associated with outcomes in the logistic regression analysis.

\section{Treatment process}

Treatment in the field was provided by emergency physicians. All patients had quick examination with documentation of vital signs. Rapid sequence intubation facilitated by hypnotics and relaxants, ventilation, treatment of hemorrhage, and fluid resuscitation was done as appropriate. After hospital admission each patient was examined by a trauma team (anesthesiologists, trauma surgeons, and/or neurosurgeons, radiologists, nurses), and a computed tomography (CT) scan was done. The patients then underwent surgery as appropriate and/or were admitted to the intensive care unit (ICU). Intensive care was provided by anesthesiologists in cooperation with neuro or trauma surgeons.

\section{Data collection}

Basic demographic data of the patient, cause and location of trauma, prehospital status and treatment, mechanism and severity of trauma [AIS, Injury Severity Score (ISS)], results of CT scans, results of lab testing, and data on surgical procedures and outcomes was recorded prospectively. Prehospital data were documented by paramedics and then transferred into the databases. Summarized CT findings [i.e., data on basal cisterns (open/compressed/ absent), midline shift, main findings (edema, hematoma, contusions, etc.), Marshall classification] were entered into a separate CT page in the databases. No central review of CT scans was done in the first project. Central review of the CT scans was done in the second project; a radiologist and a trauma surgeon checked the accuracy of the data entered into the database. Data on duration of various treatments, on complications, and on outcomes were collected at discharge from the ICU, at hospital discharge, and at 6 months after injury. The Glasgow Outcome Scale (GOS) score at 6 months after injury was evaluated by phone calls to the patients or their relatives. Data were collected by local research fellows. Data quality was monitored by INRO project managers. They reported data problems to the local researchers who then submitted the missing or corrected values. Personal data protection was observed and the identifiers were kept separately from the data.

\section{Data analysis}

All patients who had an AIS "head" $\left(\mathrm{AIS}_{\mathrm{H}}\right)<6$ and survived at least until admission to the ICU were included. Data on trauma mechanism, trauma severity, CT findings, treatment, and outcomes were retrieved for each patient. The 6-point Rotterdam CT score [6] was used to classify CT findings and to calculate probability of mortality according to this score. The prognostic scores developed by Hukkelhoven et al. [7] were used to estimate probability of hospital death $\left(P_{\mathrm{D}}\right)$ and probability of unfavorable longterm outcome $\left(P_{\mathrm{U}}\right)$. To describe long-term outcomes the 
GOS [8] was used. "Favorable outcome" was defined as a GOS score of five or four; "unfavorable outcome" was defined as a GOS score of three or less at 6 months after trauma. Patients were assigned to the group "TBI + injury" if they had one or more extracranial injuries with an AIS $>2$. Patients were assigned to the group "TBI isolated" if they had no extracranial injuries with an AIS $>2$. The differences between these two groups of patients were analyzed.

\section{Statistical analysis}

Analyses were done using the software provided by P. Wessa (Free Statistics Software version 1.1.23-r6, http:// www.wessa.net). Two-tailed $t$ test, Fisher's exact test, and $\chi^{2}$-test were done as appropriate to identify differences between the groups. To check for associations with outcomes we constructed logistic regression models for hospital death and favorable long-term outcome where outcomes were corrected for confounders, with backward exclusion of non-significant $(P>0.1)$ parameters. Age, gender, trauma mechanism, number of injured body regions with $\mathrm{AIS}>2$, ISS, $\mathrm{AIS}_{\mathrm{H}}$, GCS score, pupillary reactivity, presence of hypoxia and hypotension, Rotterdam CT score, and requirement of neurosurgery or extracranial surgery were considered possible confounders. The models were calculated for both groups individually, and for the whole sample as well. Data are presented as means with standard deviations, or as proportions. A $P$ value of $<0.05$ was considered statistically significant.

\section{Results}

There were 863 data sets in the database. Of these, hospital outcomes were missing in $17(1.9 \%)$ patients, $10(1.2 \%)$ patients died prior to ICU admission, data on additional injuries were missing in $14(1.6 \%)$ patients, and 55 $(6.4 \%)$ had an $\mathrm{AIS}_{\mathrm{H}}$ of six. This left 767 patients for analysis; of these, 403 (52.5\%) had isolated TBI, and 364 $(47.5 \%)$ had concomitant injuries. There was no significant "center effect"; all centers that enrolled $>15$ patients had mortality rates within the expected ranges. Values were outside these ranges in two centers that enrolled fewer patients, but this could be an effect of the low number of patients.

\section{Demographic data (Table 1)}

Hospital mortality was $2.8 \%$ lower in patients with concomitant injuries (n.s.). In both groups, most patients were male. Mean age was significantly higher in patients with isolated TBI $(P<0.001)$. It was also higher in females from both groups (n.s.). A significant $(P<0.01)$ increase in hospital mortality was seen with increasing age, but there was no difference in mortality rates between the groups. With regard to trauma mechanism falls and trafficrelated accidents were most common in both groups. There were no significant differences in mortality rates for any of the mechanisms.

\section{Trauma and TBI severity (Table 2)}

The ISS was significantly higher in patients with concomitant injuries $(P<0.001)$. There was an increase in the severity of concomitant injuries for increasing values of $\mathrm{AIS}_{\mathrm{H}}$ : the values for ISS (calculated without $\mathrm{AIS}_{\mathrm{H}}$ ) were $19.7 \pm 8.6\left(\mathrm{AIS}_{\mathrm{H}}=2\right), 22.8 \pm 11.0\left(\mathrm{AIS}_{\mathrm{H}}=3\right), 20.0 \pm$ $10.3\left(\mathrm{AIS}_{\mathrm{H}}=4\right)$, and $27.9 \pm 16.6\left(\mathrm{AIS}_{\mathrm{H}}=5\right)$, respectively $\left(P=0.1\right.$, n.s.). Mean $\mathrm{AIS}_{\mathrm{H}}$ and mean GCS scores were not different. Within each group ISS and $\mathrm{AIS}_{\mathrm{H}}$ were significantly higher and GCS scores were significantly lower in non-survivors. In both groups, most of the patients had severe TBI: only $17 / 767$ [2.2\%; if $\left(\mathrm{AIS}_{\mathrm{H}}>2\right)$ is used as definition] or 95/767 [12.4\%; if (GCS score >8) is used as definition] of the patients had moderate TBI. In patients with $\mathrm{AIS}_{\mathrm{H}}=2$ mortality was significantly lower in those with isolated TBI. Increasing GCS scores were associated with significant decreases in mortality rates in both groups. In both groups, patients with reactive pupils had significantly lower mortality rates but there were no significant differences in mortality rates between the groups. The same was true for absence of prehospital hypotension and hypoxia, respectively. Incidences of aspiration, use of anticoagulants, and comorbidities were not significantly different between the groups, and these had no significant effects upon mortality. The predicted $P_{\mathrm{D}}$ was $29.2 \pm$ $20.5 \%$ for patients with concomitant injuries, and was $33.4 \pm 21.5 \%$ for patients with isolated TBI $(P=0.06)$, and the $P_{\mathrm{U}}$ values were $50.9 \pm 24.0 \%$ and $54.9 \pm$ $24.6 \%$, respectively $(P=0.02)$.

\section{CT findings}

Mortality increased significantly with increasing Rotterdam CT scores $(P<0.001)$, but there were no significant mortality differences between the groups. The mortality rates were lower than those predicted by the Rotterdam score; a significant correlation $(y=15.963 x-2.388$; $\left.R^{2}=0.992 ; P=0.03\right)$ between observed and predicted values was found for patients with isolated TBI only. With regard to predominant lesions, subdural hematoma was observed most frequently, followed by contusion, EDH and subarachnoid hemorrhage. The overall distribution of predominant lesions was not significantly different between the groups. There were no differences in mortality between 
Table 1 Gender, age and trauma mechanism

\begin{tabular}{|c|c|c|c|c|c|c|c|}
\hline & \multicolumn{2}{|c|}{ TBI + injury } & \multicolumn{2}{|c|}{ TBI isolated } & \multicolumn{2}{|l|}{ Total } & \multirow[t]{2}{*}{$P$ value } \\
\hline & $n$ & $\%$ mort & $n$ & $\%$ mort & $n$ & $\%$ mort & \\
\hline Patients & 364 & 27.2 & 403 & 30.0 & 767 & 28.7 & 0.42 \\
\hline Female & 85 & 27.1 & 117 & 33.3 & 202 & 30.7 & - \\
\hline Male & 279 & 27.2 & 286 & 28.7 & 565 & 28.0 & - \\
\hline$\%$ female & 23 & & 29 & & 26 & & \\
\hline Age & Mean & SD & Mean & SD & Mean & SD & \\
\hline Females & 45.9 & 23.3 & 60.8 & 22.4 & 54.5 & 23.9 & - \\
\hline Males & 43.0 & 20.4 & 49.5 & 21.4 & 46.3 & 21.1 & - \\
\hline All patients & 43.6 & 21.1 & 52.8 & 22.2 & 48.5 & 22.2 & - \\
\hline Trauma mechanism & $n$ & $\%$ mort & $\mathrm{n}$ & $\%$ mort & $\mathrm{n}$ & $\%$ mort & \\
\hline Fall $<3 \mathrm{~m}$ & 52 & 36.5 & 180 & 41.7 & 232 & 40.5 & 0.52 \\
\hline Fall $>3 \mathrm{~m}$ & 56 & 32.1 & 23 & 17.4 & 79 & 27.8 & 0.27 \\
\hline Traffic-related & 197 & 23.9 & 99 & 21.2 & 296 & 23.0 & 0.66 \\
\hline Sports-related & 25 & 12.0 & 33 & 9.1 & 58 & 10.3 & 0.99 \\
\hline Work-related/no falls & 7 & 28.6 & 11 & 18.2 & 18 & 22.2 & 0.99 \\
\hline Violence & 3 & 33.3 & 14 & 35.7 & 17 & 35.3 & 0.99 \\
\hline Other & 19 & 31.6 & 21 & 23.8 & 40 & 27.5 & 0.73 \\
\hline Unknown & 5 & 60.0 & 22 & 27.3 & 27 & 33.3 & 0.30 \\
\hline Total & 364 & 27.2 & 403 & 30.0 & 767 & 28.7 & 0.42 \\
\hline \multicolumn{8}{|l|}{ Type of trauma } \\
\hline Blunt & 327 & 28.1 & 375 & 29.9 & 702 & 29.1 & 0.62 \\
\hline Penetrating & 27 & 18.5 & 18 & 44.4 & 45 & 28.9 & 0.09 \\
\hline Unknown & 10 & 20.0 & 10 & 10.0 & 20 & 15.0 & 0.99 \\
\hline Total & 364 & 27.2 & 403 & 30.0 & 767 & 28.7 & 0.42 \\
\hline
\end{tabular}

The $P$ value relates to the mortality difference between patients with isolated TBI and patients with concomitant injuries

$T B I$ traumatic brain injury

the two groups within the different classes of the Marshall CT score (Table 2).

\section{Treatment factors (Table 3)}

Most patients were admitted directly to the study centers; mortality was lower in the 125 patients $(16.3 \%)$ with indirect transfer $(P=0.002)$. Air and ground transport were associated with comparable mortality rates. Patients who required prehospital airway management had a significantly $(P=0.008)$ higher mortality. There were no differences regarding the intervals between admission and start of CT scan, and between start of CT scan and start of surgery. The majority of the patients $(n=504 ; 65.7 \%)$ were managed conservatively and had either no surgical procedure or insertion of an ICP monitoring device only. Mortality was lower in the patients who had primary craniectomy than in those who had craniotomy $(P=0.053)$. The requirement for extracranial surgery was associated with significantly higher mortality in patients with concomitant injuries. Duration of ventilation $(12.8 \pm 11.2$ vs. $10.1 \pm 10.8$ days $)$, ICU stay $(22.0 \pm 18.5$ vs. $17.4 \pm 16.3$ days $)$, and hospital stay $(42.0 \pm 39.4$ vs. $28.2 \pm 25.6$ days $)$ were significantly shorter in survivors with isolated TBI than in those with concomitant injuries. No significant differences regarding these parameters were found in non-survivors.

\section{Concomitant injuries (Table 4)}

Injuries to the thoracic region and to extremities were associated with higher, isolated injuries to the face with lower mortality. None of the observed mortality rates was significantly different from the average mortality for the whole group. The overall incidences of associated injuries were: $191(24.9 \%)$ patients had thoracic, $166(21.6 \%)$ had facial, 154 (20.1\%) had extremity, 58 (7.6\%) had spinal, $20(2.6 \%)$ had abdominal, and $6(0.8 \%)$ had external injuries. Of the 58 spinal injuries, 20 (34.5\%; $2.6 \%$ of all) were cervical, 28 (48.3\%; $3.7 \%$ of all) were thoracic, and $10(17.2 \% ; 1.3 \%$ of all $)$ were lumbar spine injuries. 
Table 2 Trauma severity

\begin{tabular}{|c|c|c|c|c|c|c|c|}
\hline & \multicolumn{2}{|c|}{ TBI + injury } & \multicolumn{2}{|c|}{ TBI isolated } & \multicolumn{2}{|l|}{ Total } & \multirow[t]{2}{*}{$P$ value } \\
\hline & Mean & SD & Mean & SD & Mean & SD & \\
\hline ISS & 34.4 & 11.0 & 18.2 & 5.5 & 25.9 & 11.8 & - \\
\hline $\mathrm{AIS}_{\mathrm{H}}$ & 3.95 & 0.66 & 4.06 & 0.68 & 4.01 & 0.67 & - \\
\hline GCS score & 5.62 & 2.68 & 5.57 & 2.77 & 5.59 & 2.72 & - \\
\hline $\mathrm{AIS}_{\mathrm{H}}$ & $n$ & $\%$ mort & $n$ & $\%$ mort & $n$ & $\%$ mort & \\
\hline 2 & 9 & 33.3 & 8 & 12.5 & 17 & 23.5 & 0.05 \\
\hline 3 & 62 & 14.5 & 58 & 6.9 & 120 & 10.8 & 0.24 \\
\hline 4 & 231 & 19.9 & 240 & 24.2 & 471 & 22.1 & 0.27 \\
\hline 5 & 62 & 66.1 & 97 & 59.8 & 159 & 62.3 & 0.50 \\
\hline Total & 364 & 27.2 & 403 & 30.0 & 767 & 28.7 & 0.42 \\
\hline \multicolumn{8}{|l|}{ GCS score } \\
\hline 3 & 132 & 41.7 & 148 & 43.9 & 280 & 42.9 & 0.72 \\
\hline 4 & 24 & 29.2 & 39 & 61.5 & 63 & 49.2 & 0.02 \\
\hline 5 & 29 & 27.6 & 34 & 23.5 & 63 & 25.4 & 0.7 \\
\hline 6 & 57 & 29.8 & 53 & 20.8 & 110 & 25.5 & 0.38 \\
\hline 7 & 41 & 14.6 & 41 & 12.2 & 82 & 13.4 & 0.99 \\
\hline 8 & 38 & 5.3 & 36 & 19.4 & 74 & 12.2 & 0.08 \\
\hline $9-12$ & 43 & 9.3 & 52 & 1.9 & 95 & 5.3 & 0.17 \\
\hline Total & 364 & 27.2 & 403 & 30.0 & 767 & 28.7 & 0.42 \\
\hline \multicolumn{8}{|l|}{ Marshall score } \\
\hline Diffuse injury 1 & 43 & 11.6 & 19 & 5.3 & 62 & 9.7 & 0.44 \\
\hline Diffuse injury 2 & 97 & 24.7 & 73 & 13.7 & 170 & 20.0 & 0.08 \\
\hline Diffuse injury 3 & 39 & 35.9 & 26 & 38.5 & 65 & 36.9 & 0.83 \\
\hline Diffuse injury 4 & 5 & 60.0 & 3 & 66.7 & 8 & 62.5 & - \\
\hline Evacuated lesion & 90 & 32.2 & 173 & 35.3 & 263 & 34.2 & 0.62 \\
\hline Non-evacuated lesion & 87 & 25.3 & 107 & 32.7 & 194 & 29.4 & 0.26 \\
\hline Not determined & 3 & 66.7 & 2 & 100.0 & 5 & 80.0 & - \\
\hline Total & 364 & 27.2 & 403 & 30.0 & 767 & 28.7 & 0.42 \\
\hline
\end{tabular}

The $P$ value relates to the mortality difference between patients with isolated TBI and patients with concomitant injuries

TBI traumatic brain injury; $A I S_{H}$ Abbreviated Injury Score for the region "head"; ISS Injury Severity Score; GCS Glasgow Coma Scale

Treatment of concomitant injuries (Table 5)

More than half of the injuries did not require surgical interventions. The number of surgical procedures required was not significantly associated with mortality rates. Orthopedic procedures involving extremities or pelvic region were done most frequently. Abdominal surgery and thoracic surgery were associated with higher mortality rates.

\section{Outcomes}

The observed hospital mortality was $27.2 \%$ for patient with concomitant injuries and $30.0 \%$ for patients with isolated TBI, while $P_{\mathrm{M}}$ values were $29.2 \pm 20.5 \%$ and $33.4 \pm 21.5 \%$, respectively. The observed vs. expected ratio $(\mathrm{O} / \mathrm{E}$ ratio) for mortality was 0.93 for patients with concomitant injuries (=25 unexpected survivors), the O/E ratio for mortality was 0.90 for patients with isolated TBI (=40 unexpected survivors). Main causes of death in patients with concomitant injuries were brain death $(51.9 \%)$, cardiovascular problems $(31.5 \%)$, multiple organ failure $(9.8 \%)$, major hemorrhage $(4.4 \%)$, and acute respiratory distress syndrome $(2.2 \%)$. In patients with isolated TBI brain death was observed significantly more frequently $(65.1 \%, P=0.04)$, and the rates of cardiovascular death $(25.7 \%)$ and multiple organ failure $(5.5 \%)$ were lower. Long-term outcome was unknown in 28 patients (14 from each group). Favorable outcome was observed in $54.4 \%(198 / 364)$ of patients with concomitant injuries and in $46.2 \%(186 / 403)$ of the patients with isolated TBI; this difference was significant $(P=0.02)$. Unfavorable long-term outcome was observed in $41.8 \%$ (152/364) and $50.4 \%$ (203/403), respectively; this difference 
Table 3 Treatment

\begin{tabular}{|c|c|c|c|c|c|c|c|}
\hline & \multicolumn{2}{|c|}{ TBI + injury } & \multicolumn{2}{|c|}{ TBI isolated } & \multicolumn{2}{|c|}{ Total } & \multirow[t]{2}{*}{$P$ value } \\
\hline & $n$ & $\%$ mort & $n$ & $\%$ mort & $n$ & $\%$ mort & \\
\hline \multicolumn{8}{|l|}{ Indirect transfer } \\
\hline No & 321 & 29.3 & 321 & 32.4 & 642 & 30.8 & 0.44 \\
\hline Yes & 43 & 11.6 & 82 & 20.7 & 125 & 17.6 & 0.23 \\
\hline \multicolumn{8}{|l|}{ Mode of transport } \\
\hline Air & 175 & 26.3 & 139 & 26.6 & 314 & 26.4 & 0.99 \\
\hline Ground & 177 & 29.9 & 248 & 33.5 & 425 & 32.0 & 0.46 \\
\hline Unknown & 12 & 0.0 & 16 & 6.3 & 28 & 3.6 & 0.99 \\
\hline \multicolumn{8}{|l|}{ Prehospital intubation } \\
\hline No & 76 & 21.1 & 148 & 22.3 & 224 & 21.9 & 0.87 \\
\hline Yes & 288 & 28.8 & 255 & 34.5 & 543 & 31.5 & 0.17 \\
\hline \multicolumn{8}{|l|}{ Neurosurgery } \\
\hline No neurosurgery & 107 & 27.1 & 125 & 24.8 & 232 & 25.9 & 0.76 \\
\hline ICP monitoring only & 167 & 24.6 & 105 & 27.6 & 272 & 25.7 & 0.57 \\
\hline ASDH evacuation & 45 & 33.3 & 121 & 39.7 & 166 & 38.0 & 0.48 \\
\hline EDH evacuation & 28 & 25.0 & 27 & 29.6 & 55 & 27.3 & 0.77 \\
\hline ICH evacuation & 5 & 40.0 & 9 & 11.1 & 14 & 21.4 & 0.51 \\
\hline$>1$ lesion evacuated & 7 & 42.9 & 14 & 14.3 & 21 & 23.8 & 0.28 \\
\hline Primary decompressive surgery & 5 & 40.0 & 2 & 100.0 & 7 & 57.1 & 0.43 \\
\hline Total & 364 & 27.2 & 403 & 30.0 & 767 & 28.7 & 0.42 \\
\hline Secondary decompressive surgery & 6 & 50.0 & 5 & 60.0 & 11 & 54.5 & 0.86 \\
\hline \multicolumn{8}{|l|}{ Technique } \\
\hline Decompressive surgery & 11 & 54.5 & 8 & 62.5 & 19 & 57.9 & 0.99 \\
\hline Craniectomy & 36 & 27.8 & 63 & 28.6 & 99 & 28.3 & 0.99 \\
\hline Craniotomy & 43 & 30.2 & 102 & 37.3 & 145 & 35.2 & 0.45 \\
\hline Total & 90 & 30.2 & 173 & 37.3 & 263 & 28.7 & 0.94 \\
\hline \multicolumn{8}{|l|}{ ICP monitoring } \\
\hline No & 124 & 28.2 & 177 & 25.4 & 301 & 26.6 & 0.60 \\
\hline Yes & 240 & 26.7 & 226 & 33.6 & 466 & 30.0 & 0.11 \\
\hline \multicolumn{8}{|l|}{ Extracranial surgery } \\
\hline No & 201 & 28.9 & 376 & 32.2 & 577 & 31.0 & 0.45 \\
\hline Yes & 163 & 25.2 & 27 & 0.0 & 190 & 21.6 & 0.002 \\
\hline
\end{tabular}

The $P$ value relates to the mortality difference between patients with isolated TBI and patients with concomitant injuries

TBI traumatic brain injury; ICP intracranial pressure; $A S D H$ acute subdural hematoma; $E D H$ epidural hematoma; $I C H$ intracerebral hemorrhage

was also significant $(P=0.02)$. The $P_{\mathrm{U}}$ predicted by the Hukkelhoven score was $50.9 \pm 24 \%$ for patients with associated injuries, and was $54.1 \pm 24.1 \%$ for patients with isolated TBI. The $\mathrm{O} / \mathrm{E}$ ratio for unfavorable outcome was 0.82 for patients with concomitant injuries $(=66$ patients with unexpected favorable outcome), the $\mathrm{O} / \mathrm{E}$ ratio for unfavorable outcome was 0.93 for patients with isolated TBI (=28 patients with unexpected favorable outcome). Factors that significantly influenced outcomes are listed in Table 6. Age, GCS score, pupillary reactivity, AIS $_{\mathrm{H}}$ and CT score were significant in all or almost all analyses. Isolated TBI was significantly associated with unfavorable long-term outcome. Major neurosurgery was associated with higher mortality in patients with isolated TBI, ISS was associated with worse long-term outcomes in patients with concomitant injuries.

\section{Discussion}

The overall rates of hospital mortality and unfavorable outcomes seen in this study are comparable to the outcomes reported for European centers [9]. With regard to factors influencing outcomes, age is one of the most important. This has been demonstrated in the large study done by Hukkelhoven et al. [10], and by a number of 
Table 4 Concomitant injury pattern

All injuries or combinations of injuries with an incidence of $>2 \%$ in the 364 patients with traumatic brain injuries and concomitant injuries are listed

\begin{tabular}{llllll}
\hline Outcome & Alive & Dead & Total & $\%$ of all & $\%$ mort \\
$n$ & $n$ & $n$ & & \\
\hline
\end{tabular}

Injured body regions

\begin{tabular}{|c|c|c|c|c|c|}
\hline Face & 55 & 13 & 68 & 18.7 & 19.1 \\
\hline Thorax & 36 & 15 & 51 & 14.0 & 29.4 \\
\hline Extremities & 24 & 16 & 40 & 11.0 & 40.0 \\
\hline Thorax + extremities & 13 & 10 & 23 & 6.3 & 43.5 \\
\hline Face + thorax & 19 & 2 & 21 & 5.8 & 9.5 \\
\hline Face + extremities & 16 & 4 & 20 & 5.5 & 20.0 \\
\hline Face + thorax + extremities & 12 & 7 & 19 & 5.2 & 36.8 \\
\hline Thorax + abdomen & 14 & 2 & 16 & 4.4 & 12.5 \\
\hline Thorax + abdomen + extremities & 8 & 5 & 13 & 3.6 & 38.5 \\
\hline Thoracal spine & 9 & 2 & 11 & 3.0 & 18.2 \\
\hline Abdomen & 8 & 2 & 10 & 2.7 & 20.0 \\
\hline Other & 51 & 21 & 72 & 19.8 & 29.2 \\
\hline Total & 265 & 99 & 364 & 100.0 & 27.2 \\
\hline
\end{tabular}

Table 5 Surgery in 364 patients with TBI plus concomitant injuries

\begin{tabular}{lrrrrr}
\hline Outcome & Alive & Dead & Total & \% of all & $\%$ mort \\
\hline Number of surgical procedures & & & & \\
0 & 142 & 58 & 200 & 54.9 & 29.0 \\
1 & 71 & 27 & 98 & 26.9 & 27.6 \\
2 & 38 & 9 & 47 & 12.9 & 19.1 \\
3 & 11 & 1 & 12 & 3.3 & 8.3 \\
4 & 3 & 3 & 6 & 1.6 & 50.0 \\
5 & & 1 & 1 & 0.3 & 100.0 \\
Total & 265 & 99 & 364 & 100.0 & 27.2 \\
Region of surgery & & & & & \\
Lower extremity & 49 & 19 & 68 & 26.5 & 27.9 \\
Face & 43 & 7 & 50 & 19.5 & 14.0 \\
Thorax & 32 & 16 & 48 & 18.7 & 33.3 \\
Upper extremity & 29 & 6 & 35 & 13.6 & 17.1 \\
Abdomen & 18 & 13 & 31 & 12.1 & 41.9 \\
Pelvis & 5 & 3 & 8 & 3.1 & 37.5 \\
Cervical spine & 6 & 1 & 7 & 2.7 & 14.3 \\
Thoracic spine & 7 & 0 & 7 & 2.7 & 0.0 \\
Lumbar spine & 3 & 0 & 3 & 1.2 & 0.0 \\
Total & 192 & 65 & 257 & 100.0 & 25.3 \\
\hline
\end{tabular}

$S P$ surgical procedures; $\%$ of all percentage of surgical procedures in the 364 patients with traumatic brain injury and concomitant injuries; $\%$ of SP percentage of all surgical procedures

other studies. The significant effect of age has been confirmed by our results. In addition, the effects of GCS scores on outcomes after TBI have been proven beyond doubt [11]. This association was also found in our study. In the same analysis, one or both unreactive pupils were significantly associated with poor outcome [11]. This association was also confirmed in our multivariate analysis.
In this study, monitoring of ICP was done in only $70 \%$ of the patients with severe TBI. In some patients, this was probably due to poor prognosis. A previous study involving 82 Austrian ICUs found that ICP monitoring was not done in patients whose prognosis was either poor or good; the highest rates of ICP monitoring were found in the patients with an "intermediate" prognosis [12]. A recent study from the Netherlands reported that ICP was monitored in only $46 \%$ of patients with severe TBI; higher age was one of the reasons not to monitor ICP [13].

One of the earlier studies on TBI and concomitant injuries [14] found that only $42 \%$ of the patients had isolated TBI, and that concomitant injuries had effects on long-term outcomes only if they involved at least two or more body regions. A Swiss study [3] reported that $59 \%$ of their 139 patients with EDH had isolated TBI, and that concomitant injuries had no effects on outcomes, and a study from the Germany [15] came to the same conclusion. In their analysis of a large German database, Lefering et al. [2] found significantly increased mortality rates in patients whose torso or extremity injuries had an AIS of five or six. No such effect was observed in our study, but this could be due to the much smaller sample of patients. Thus, most studies concluded that concomitant injuries had either no effect on outcomes, or had effects only if the injuries were of high severity. This is in accordance with our results; isolated TBI was actually associated with worse outcomes. A similar result was found in the study by Martins et al. [16]; in their study, mortality was significantly higher in patients with isolated TBI (37.6 vs. $27.6 \% ; P=0.004)$.

In our study, mortality was significantly higher in the patients with concomitant injury and an $\mathrm{AIS}_{\mathrm{H}}$ of two. This could be an effect of the fact that only patients who were admitted to the ICU were included. Thus, ICU admission 
Table 6 Factors that significantly $(P<0.01)$ influenced the outcomes

\begin{tabular}{|c|c|c|c|c|}
\hline \multirow[b]{2}{*}{ TBI isolated } & \multicolumn{2}{|l|}{ Hospital death } & \multicolumn{2}{|c|}{ Long-term outcome } \\
\hline & Parameter & $P$ value & Parameter & $P$ value \\
\hline & Age & $<0.001$ & Age & $<0.001$ \\
\hline & $\mathrm{AIS}_{\mathrm{H}}$ & $<0.001$ & $\mathrm{AIS}_{\mathrm{H}}$ & $<0.001$ \\
\hline & Pupils & 0.002 & GCS score & $<0.001$ \\
\hline & GCS score & $<0.001$ & CT score & $<0.001$ \\
\hline & CT score & 0.007 & & \\
\hline & Neurosurgery & 0.003 & & \\
\hline \multicolumn{5}{|l|}{ TBI + injury } \\
\hline & Age & $<0.001$ & Age & $<0.001$ \\
\hline & $\mathrm{AIS}_{\mathrm{H}}$ & 0.004 & Pupils & $<0.001$ \\
\hline & Pupils & $<0.001$ & GCS score & $<0.001$ \\
\hline & GCS score & 0.005 & ISS & $<0.001$ \\
\hline \multicolumn{5}{|l|}{ All patients } \\
\hline & Age & $<0.001$ & Age & $<0.001$ \\
\hline & $\mathrm{AIS}_{\mathrm{H}}$ & $<0.001$ & Pupils & 0.002 \\
\hline & Pupils & $<0.001$ & GCS score & $<0.001$ \\
\hline & GCS score & $<0.001$ & CT score & 0.001 \\
\hline & CT score & $<0.001$ & Isolated TBI & 0.007 \\
\hline
\end{tabular}

$A I S_{H}$ Abbreviated Injury Score for the region "head"; GCS Glasgow Coma Scale; $C T$ computed tomography; ISS injury severity score; $T B I$ traumatic brain injury

of patients with an $\mathrm{AIS}_{\mathrm{H}}$ of two may have been due to extracranial rather than intracranial injuries. However, it seems obvious that the effect of extracranial injuries would be more pronounced in patients with low severity of TBI. In a study on mild TBI [17] significant effects of extracranial injuries on duration and outcomes of rehabilitation were found.

Our study found a high incidence $(21.6 \%)$ of facial trauma. It has been suggested that facial fractures protect the brain from severe injury, but this has been proven wrong [18]: of the 3,040 patients with TBI, 848 (27.9\%) were found to have facial fractures, and TBI severity was not different between the patients with and without facial trauma. The rates of additionally injured regions were comparable to those published by Martins et al. [16]. Compared to our data, Rickels et al. [19] found higher rates of facial trauma (58\%) and lower rates for all other concomitant injuries; however, this study included mostly patients with mild TBI.

Regarding causes of death Kemp et al. [1] compared data from 54 non-survivors with isolated TBI to those from 81 non-survivors with concomitant injuries. Their data are not fully comparable to those from our study because they also included patients with non-survivable TBI; they found, however, that brain death occurred more frequently in cases of isolated TBI, and that respiratory failure occurred significantly more frequently in patients with multiple trauma (43.2 vs. $20.4 \%$ ). A comparable pattern was seen in our study.

Contrary to previous reports, we found that indirect transfer was associated with lower mortality rates. Hartl et al. [20] reported that indirect transfer was associated with a $50 \%$ increase in mortality for patients with severe TBI. The difference may be due to the low number of patients with indirect transfer in our study.

Limitations of the study

The scores used to estimate $P_{\mathrm{M}}$ and $P_{\mathrm{U}}$ have not been validated for our study population. These scores have been created from the international and North American data from the tirilazad trial [21, 22], and have been validated against the core data set of the European Brain Injury Consortium (EBIC) survey [23] and data from the Traumatic Coma Data Bank [24]. It is quite likely that our patients are comparable to those from the EBIC centers and the international arm of the tirilazad trial. There could, however, be subtle differences, and the $\mathrm{O} / \mathrm{E}$ ratios estimated for our groups of patients may be incorrect.

\section{Conclusions}

The study showed that concomitant injuries were found in nearly half of the patients. Hospital mortality was $2.8 \%$ higher, and the rate of unfavorable outcome was $8.6 \%$ higher in patients with isolated TBI. Concomitant injuries were associated with significantly higher mortality in the few patients with $\mathrm{AIS}_{\mathrm{H}}=2$. Concomitant injuries were also associated with longer duration of ventilation, and longer ICU and hospital stay. We were unable to find any significant effects of treatment. The worst outcomes of patients with isolated TBI were mainly due to a significantly higher mean age. The main factors that influenced the outcomes were age, GCS score, pupillary reactivity, $\mathrm{AIS}_{\mathrm{H}}$ and CT score.

Acknowledgments The data used for this study were collected for a project funded by the Austrian Worker's Compensation Board (AUVA; FK 33/2003) and by the "Jubilee Fund" of the Austrian National Bank (Project 8987), and for a project funded by the Ministry of Health (Contract Oct. 15, 2008) and the AUVA (FK 11/2008 and FK 11/2010). INRO is supported by an annual grant from Mrs. Ala Auersperg-Isham and Mr. Ralph Isham, and by small donations from various sources.

Conflicts of interest The authors are not aware of any conflicts of interest. 
Open Access This article is distributed under the terms of the Creative Commons Attribution License which permits any use, distribution, and reproduction in any medium, provided the original author(s) and the source are credited.

\section{Appendix: Austrian Severe TBI Study Group}

Investigators from the participating centers: H. Artmann MD (Schwarzach), N. Bauer MD (Linz UKH), F. Botha MD (Linz WJ), F. Chmeliczek MD (Salzburg LKA), G. Clarici MD (Graz Uni), D. Csomor MD (Wr. Neustadt), R. Folie MD (Feldkirch), R. Germann MD, PhD (Feldkirch), F. Gruber MD (Linz AKH), H-D. Gulle MD (Klagenfurt), T. Haidacher MD (Graz UKH), G. Herzer MD (Wr. Neustadt), P. Hohenauer MD (Salzburg LKA), A. Hüblauer MD (Horn), J. Lanner MD (Salzburg UKH), V. Lorenz MD (Wien UKH XII), C. Mirth MD (St. Pölten), W. Mitterndorfer MD (Linz AKH), W. Moser MD (Klagenfurt), H. Schmied MD (Amstetten), K-H Stadlbauer MD, PhD (Innsbruck), H. Steltzer MD, PhD (Wien UKH XII), Ernst Trampitsch MD (Klagenfurt), A. Waltensdorfer MD (Graz Uni), A. Zechner MD (Klagenfurt); INRO researchers: M. Rusnak MD, PhD (Epidemiology, Public Health), I. Janciak PhD (IT support, database management)

\section{References}

1. Kemp CD, Johnson JC, Riordan WP, Cotton BA (2008) How we die: the impact of nonneurologic organ dysfunction after severe traumatic brain injury. Am Surg 74(9):866-872

2. Lefering R, Paffrath T, Linker R, Bouillon B, Neugebauer EA (2008) Head injury and outcome-what influence do concomitant injuries have? J Trauma 65(5):1036-1043. doi:10.1097/TA.0b0 13e318184ee48 (discussion 1043-1044)

3. Heinzelmann M, Platz A, Imhof HG (1996) Outcome after acute extradural haematoma, influence of additional injuries and neurological complications in the ICU. Injury 27(5):345-349. doi: 0020138395002235

4. Rusnak M, Janciak I, Majdan M, Wilbacher I, Mauritz W (2007) Severe traumatic brain injury in Austria VI: effects of guidelinebased management. Wien Klin Wochenschr 119(1-2):64-71. doi: 10.1007/s00508-006-0765-0

5. Bullock R, Chesnut RM, Clifton G, Ghajar J, Marion DW, Narayan RK, Newell DW, Pitts LH, Rosner MJ, Wilberger JW (1996) Guidelines for the management of severe head injury. Brain Trauma Foundation. Eur J Emerg Med 3(2):109-127

6. Maas AI, Hukkelhoven CW, Marshall LF, Steyerberg EW (2005) Prediction of outcome in traumatic brain injury with computed tomographic characteristics: a comparison between the computed tomographic classification and combinations of computed tomographic predictors. Neurosurgery 57(6):1173-1182 (discussion: 1173-1182, pii: 00006123-200512000-00013)

7. Hukkelhoven CW, Steyerberg EW, Habbema JD, Farace E, Marmarou A, Murray GD, Marshall LF, Maas AI (2005) Predicting outcome after traumatic brain injury: development and validation of a prognostic score based on admission characteristics. J Neurotrauma 22(10):1025-1039. doi:10.1089/neu.2005.22.1025
8. Jennett B, Bond M (1975) Assessment of outcome after severe brain damage. Lancet 1(7905):480-484

9. Tagliaferri F, Compagnone C, Korsic M, Servadei F, Kraus J (2006) A systematic review of brain injury epidemiology in Europe. Acta Neurochir (Wien) 148(3):255-268. doi:10.1007/ s00701-005-0651-y (discussion: 268)

10. Hukkelhoven CW, Steyerberg EW, Rampen AJ, Farace E, Habbema JD, Marshall LF, Murray GD, Maas AI (2003) Patient age and outcome following severe traumatic brain injury: an analysis of 5600 patients. J Neurosurg 99(4):666-673

11. Marmarou A, Lu J, Butcher I, McHugh GS, Murray GD, Steyerberg EW, Mushkudiani NA, Choi S, Maas AI (2007) Prognostic value of the Glasgow Coma Scale and pupil reactivity in traumatic brain injury assessed pre-hospital and on enrollment: an IMPACT analysis. J Neurotrauma 24(2):270-280. doi:10.1089/neu.2006.0029

12. Mauritz W, Steltzer H, Bauer P, Dolanski-Aghamanoukjan L, Metnitz P (2008) Monitoring of intracranial pressure in patients with severe traumatic brain injury: an Austrian prospective multicenter study. Intensive Care Med 34(7):1208-1215. doi: 10.1007/s00134-008-1079-7

13. Biersteker HA, Andriessen TM, Horn J, Franschman G, van der Naalt J, Hoedemaekers CW, Lingsma HF, Haitsma I, Vos PE (2012) Factors influencing intracranial pressure monitoring guideline compliance and outcome after severe traumatic brain injury. Crit Care Med 40(6):1914-1922. doi:10.1097/CCM. 0b013e3182474bde

14. Groswasser Z, Cohen M, Blankstein E (1990) Polytrauma associated with traumatic brain injury: incidence, nature and impact on rehabilitation outcome. Brain Inj 4(2):161-166

15. Sarrafzadeh AS, Peltonen EE, Kaisers U, Kuchler I, Lanksch WR, Unterberg AW (2001) Secondary insults in severe head injury-do multiply injured patients do worse? Crit Care Med 29(6):1116-1123

16. Martins ET, Linhares MN, Sousa DS, Schroeder HK, Meinerz J, Rigo LA, Bertotti MM, Gullo J, Hohl A, Dal-Pizzol F, Walz R (2009) Mortality in severe traumatic brain injury: a multivariate analysis of 748 Brazilian patients from Florianopolis city. J Trauma 67(1):85-90. doi:10.1097/TA.0b013e318187acee000 05373-200907000-00015

17. Stulemeijer M, van der Werf SP, Jacobs B, Biert J, van Vugt AB, Brauer JM, Vos PE (2006) Impact of additional extracranial injuries on outcome after mild traumatic brain injury. J Neurotrauma 23(10):1561-1569. doi:10.1089/neu.2006.23.1561

18. Martin RC 2nd, Spain DA, Richardson JD (2002) Do facial fractures protect the brain or are they a marker for severe head injury? Am Surg 68(5):477-481

19. Rickels E, von Wild K, Wenzlaff P (2010) Head injury in Germany: a population-based prospective study on epidemiology, causes, treatment and outcome of all degrees of head-injury severity in two distinct areas. Brain Inj 24(12):1491-1504. doi: 10.3109/02699052.2010.498006

20. Hartl R, Gerber LM, Iacono L, Ni Q, Lyons K, Ghajar J (2006) Direct transport within an organized state trauma system reduces mortality in patients with severe traumatic brain injury. J Trauma 60(6):1250-1256. doi:10.1097/01.ta.0000203717.57821.8d (discussion: 1256)

21. Hukkelhoven CW, Steyerberg EW, Farace E, Habbema JD, Marshall LF, Maas AI (2002) Regional differences in patient characteristics, case management, and outcomes in traumatic brain injury: experience from the tirilazad trials. J Neurosurg 97(3):549-557

22. Marshall LF, Maas AI, Marshall SB, Bricolo A, Fearnside M, Iannotti F, Klauber MR, Lagarrigue J, Lobato R, Persson L, Pickard JD, Piek J, Servadei F, Wellis GN, Morris GF, Means ED, Musch B (1998) A multicenter trial on the efficacy of using tirilazad mesylate in cases of head injury. J Neurosurg 89(4):519-525 
23. Murray GD, Teasdale GM, Braakman R, Cohadon F, Dearden M, Iannotti F, Karimi A, Lapierre F, Maas A, Ohman J, Persson L, Servadei F, Stocchetti N, Trojanowski T, Unterberg A (1999) The European Brain Injury Consortium survey of head injuries. Acta Neurochir (Wien) 141(3):223-236
24. Marshall LF, Becker DP, Bowers SA, Cayard C, Eisenberg H, Gross CR, Grossman RG, Jane JA, Kunitz SC, Rimel R, Tabaddor K, Warren J (1983) The National Traumatic Coma Data Bank. Part 1: design, purpose, goals, and results. J Neurosurg 59(2):276-284 